\title{
О ПОНЯТИИ «ОБЩЕНИЕ КАК ДЕЯТЕЛЬНОСТЬ» ПРИМЕНИТЕЛЬНО К ОБУЧЕНИЮ ИНОСТРАНЦЕВ В СООТВЕТСТВИИ С АНТРОПОЛОГИЧЕСКИМ ПРИНЦИПОМ ГУМАНИТАРНЫХ НАУК ${ }^{1}$
}

\section{ON THE CONCEPT OF "COMMUNICATION AS AN ACTIVITY" IN RELATION TO TEACHING FOREIGNERS IN ACCORDANCE WITH THE ANTHROPOLOGICAL PRINCIPLE HUMANITIES}

\section{Muhammad Obeed Haider Ali Lin Xciaoyue}

Summary:This article is devoted to the construction of an anthropologically oriented model of intercultural communication in Russian in the audience of foreign students. The purpose of the article is to determine the semantic structure of concepts based on the differentiation of the terms communication and communication: 1) intercultural communication; 2) intercultural communication, and also consider the features of these phenomena on the basis of such an integrative component as activity/ communication activity. The practical significance of the study lies in finding strategies of communicative interaction that are acceptable for contacting ethnocultures.

Keywords: anthropological principle, communication as an activity, communication, intercultural communication, intercultural communication.

\author{
Мухаммад Людмила Петровна \\ Д.п.н., профеессор, Московский Государственный \\ лингвистический университет, Москва \\ ludmilamuh@mail.ru \\ Оби Хайдер Али Обид \\ Московский государственный лингвистический \\ университет \\ Линь Сяоюе \\ Аспирант, Государственный институт \\ русского языка им. А.С. Пушкина
}

Аннотация: Данная статья посвящена конструированию антропологически ориентированной модели межкультурного общения на русском языке в аудитории иностранных учащихся. Цель статьи - на основе дифференциации терминов общение и коммуникация определить семантическую структуру понятий: 1) межкультурное общение; 2) межкультурная коммуникация, а также рассмотреть особенности этих феноменов на базе такого интегративного компонента, как деятельность/коммуникативная деятельность. Практическая значимость исследования состоит в нахождении приемлемых для контактирующих этнокультур стратегий коммуникативного взаимодействия.

Ключевые слова: антропологический принцип, общение как деятельность, коммуникация, межкультурное общение, межкультурная коммуникация.
В данной статье речь пойдёт о конструировании модели коммуникативного учебного взаимодействия на русском языке (далее: РЯ) применительно к обучению иностранцев в соответствии с антропологическим принципом гуманитарных наук.

Проблематика статьи связана с размытостью на сегодняшний день таких терминов, как, с одной стороны, общение и межкультурное общение, с другой - коммуникация и межкультурная коммуникация. А ведь эти термины в современной методике преподавания русского языка как иностранного (РКИ) являются базовыми. Так, уже в работах основателя современной коммуникативно-деятельностной методики преподавания РКИ А.А. Леонтьева утверждалось, что мы учим не столько языку, сколько общению на данном языке [10]. Данная установка закрепилась почти во всех современных коммуникативно-деятельностных методиках преподавания РКИ [12; 13; 23], в том числе и в вариативных, личностнодеятельностных, методиках $[1 ; 6 ; 10 ; 8]$. Кроме того, в лингводидактической науке уже стал общепризнанным факт, что общение на РЯ в иностранной аудитории - это межкультурное общение/межкультурная коммуникация [3]. Всё описанное выше свидетельствует о необходимости чёткого определения обозначенных выше терминов, а следовательно, об актуальности нашего исследования, посвящённого, в конечном итоге, созданию эффективных моделей учебного процесса, осуществляющегося как учебное коммуникативное взаимодействие. Таким образом, предметом нашего исследования является 
семантическое содержание терминов общение, коммуникация, межкультурное общение межкультурная коммуникация, а также термин общение как деятельность применительно к обучению иностранцев в соответствии с антропологическим принципом гуманитарных наук.

Цель исследования - разграничить термины общение, коммуникация, межкультурное общение, межкультурная коммуникация, общение как деятельность, определив тем самым границы их семантического содержания и, таким образом, обеспечив оптимизацию современного учебного процесса по РКИ.

В качестве методологической основы конструирования учебного процесса, рассматриваемого как учебное общение на РЯ иностранцев мы выбираем личностно-деятельностный подход к обучению, соответствующий главному принципу наук гуманитарного цикла-антропологическому [14].

Первоначально определим, каким должен быть учебный процесс, соответствующий главному принципу наук гуманитарного цикла - антропологическому. В соответствии с постулатами современной антропологической лингводидактики такой учебный процесс имеет следующие базовые признаки: 1) базируется на личностнодеятельностном подходе к обучению, что значит: а) в центре учебного процесса находится личность учащегося (в соответствии с первой составляющей термина); б) учебный процесс реализуется как межличностное учебное общение: субъект-субъектное общение преподавателя и учащегося, а также учащихся между собой; при этом общение понимается как деятельность общения (вторая составляющая термина); 2) деятельность общения реализуется в основных его видах: а) рецептивных: аудировании и чтении; б) продуктивных: говорении и письме. При этом подчеркнём, что в настоящее время в лингводидактике постулируется не столько взаимосвязь этих видов [1], сколько их интеграция, обеспечивающая оптимальность всей системы в целом [24]. Интеграция происходит:

1) в процессе общения: а) в устной форме речи: говорение - аудирование; б) в письменной форме речи: чтение - письмо (что весьма успешно работает в традиционной методике на протяжении многих лет);

2) в процессе формирования у иностранного учащегося на базе его национальной языковой картины мира вторичных функциональных систем, обеспечивающих его деятельность на изучаемом языке - РЯ, иными словами, пресуппозицию, необходимую в целях общения на иностранном языке (ИЯ) - РКИ.

Именно такая постановка вопроса свойственна методикам, основанным на базовых принципах антропологи- ческой лингводидактики: антропологическом, коммуникативном и когнитивном [24].

Как видим, представленная выше методология включает в заданные ею педагогические стратегии конструкты, основывающиеся на таких понятиях, как общение и общение как деятельность. Однако, как было заявлено ранее, кроме этих понятий современный учебный процесс оперирует и такими понятиями, как коммуникация и межкультурная коммуникация (реже - межкультурное общение). В связи с этим в заданном контексте в целях эффективного моделирования учебного процесса попытаемся разобрать, во-первых, феномены общение/коммуникация, во-вторых - межкультурная коммуникация/ межкультурное общение, в третьих - феномен общение как деятельность.

Для начала представим точки зрения, где номинации общение/коммуникация не дифференцированы. Так, Н.А. Мартынова, склоняющаяся к тому, чтобы воспринимать данные термины как синонимы, исходит из первоначального значения латинского термина «communicatio», имеющего значение «делать общим, связывать, общаться» [11, с. 148]. Таким образом, исследователь (Н.А. Мартынова) полагает, что номинации общение и коммуникация допустимо воспринимать как синонимы [11]. Тем не менее, наш анализ высказывания Н.А. Мартыновой позволил нам выделить, с одной стороны, интегральные признаки понятий коммуникация и общение (т.е. их общий, универсальный, компонент), с другой - возможно, весьма значимые дифференциальные признаки данных понятий. Так, в качестве интегральных (общих) признаков этих двух понятий мы выделяем следующие: прочесс обмена мыслями, информачией между людьми. В качестве же дифференциальных: а) процесс обмена ... переживаниями между людьми; б) обмен ... (мыслями и информацией) с помощью различных сигналов. Таким образом, хотя Н.А. Мартынова и декларирует, что общение и коммуникация - то же самое, тем не менее, её экспликации (вербализации) показывают, что эти две номинации хотя и синонимичны, тем не менее, между ними есть определённая разница. Ниже, после более детального анализа, мы ещё вернёмся к выявленным нами дифференциациям.

Далее мы в своей статье намерены опираться на те теоретические работы, в которых понятия общение и коммуникация осознанно разведены их авторами.

Начнём наш анализ с более узкого, как мы полагаем, понятия общение.

Сначала представим точку зрения на феномен общения известных учёных, а затем и нашу личную точку зрения. 
Чтобы раскрыть семантическое содержание термина общение в гуманитарно-социальных науках, приведём структуру данного содержания, представленную в работах известного российского социального психолога Г.М. Андреевой [2]. Так, в своих работах Г.М. Андреева полагает, что общение - это феномен, в содержание которого включены, как минимум, три базовых компонента: 1) коммуникация (обмен информацией); 2) интеракция (взаимодействие); 3) социальная перцепция (понимание людьми друг друга) [2].

В своих теоретических работах Х.И.А. Мухаммад считает, что из этих трёх компонентов центральным является интеракция (взаимодействие), которая уже сама по себе самоценна и, безусловно, включает и первый компонент (обмен информацией), и последний (понимание людьми друг друга), ибо ни одно корректное действие, взаимодействие (да и в целом - деятельность) невозможны: а) ни без аккумулирования информации и её обмена; б) ни без ориентировки в ситуации, т.е. понимания происходящего [15].

По мнению Н.И. Формановской, именно компонент коммуникативное взаимодействие указывает на то, что в его структуру включены носители и производители данного взаимодействия - адресант и адресат (коммуниканты), как минимум, их два [20; 15; 17]. Таким образом, общение представляет собой двусторонний процесс, действия со стороны отправителя (адресанта) и получателя информации (адресата), причём они синхронизируются, являясь своего рода «зеркальным отражением» друг друга с дифференциацией говорящего и слушающего, инициирующего общение и реагирующего на него, причём в общении (в диалоге) роли говорящего и слушающего постоянно меняются.

На основе сказанного хотелось бы назвать ещё несколько весьма важных признаков общения, выделяющих его (общение) в структуре более широкого, как мы полагаем, семантического пространства термина коммуникачия. В качестве таких признаков мы называем: 1) контактность коммуникативного взаимодействия коммуникантов; 2) относительно быструю реакцию адресата на речевые/коммуникативные действия адресанта, иными словами, обратную связь [15].

Далее в отношении понятия общение следует рассмотреть ещё один очень важный вопрос: мы знаем, что общение бывает, как минимум, двух типов:

1) общение в ситуации, когда мы с близкими людьми, в расслабленном состоянии и не контролируем свои речевые действия, мы не ставим целей для этого общения, а просто общаемся, потому что нам это нравится; такое общение чаще всего бывает в обиходно-бытовой сфере общения;

2) общение-деятельность (о чём мы уже говорили выше [10; 12]. Данное общение, как и его виды (т.е. виды речевой деятельности - РД), целенаправленно и осуществляется в процессе коммуникативного взаимодействия между адресантом (говорящим/пишущим) и адресатом (слушающим/ читающим). По нашему мнению, данное, коммуникативное, взаимодействие является основополагающим в академическом общении, когда весьма важно не просто слушать лектора, преподавателя, учащегося, но слушать и обязательно понимать. Вот это самое понимание как результирующая фаза рецептивных видов речевой деятельности (аудирования и чтения) и находится в фокусе, с одной стороны, академического взаимодействия (в учебной аудитории), с другой - социальной перцепции, а именно способности людей понимать друг друга в определённом социуме.

В свете изложенного рассмотрим феномен коммуникация в том виде, как он представлен в научной литературе, определив интегральные и дифференциальные признаки рассматриваемых двух понятий.

Как отмечалось ранее, коммуникация - это более широкое понятие по отношению к понятию общение. Думается, понятие коммуникация включает общение в качестве составного компонента. Так, по форме коммуникация может быть прямой/косвенной и опосредованной/неопосредованной. При прямой коммуникации информация адресована отправителем непосредственно получателю. В случае, если она осуществляется в устной форме и имеет в своей основе интерактивность, на основе общих (интегративных) признаков её можно квалифицировать и как коммуникацию, и как общение. В качестве интегративных признаков здесь выступают: взаимодействие, контактность, непосредственность, обратная связь.

Устная речь при этом сочетает как вербальные, так и невербальные средства общения. Причём акты взаимодействия, включающие в общение жесты и мимику, реализуются в актах их зрительного восприятия адресатом.

При письменной форме речи следует обращать внимание на такой важнейший признак, как «наличие/ отсутствие обратной связи». Например, большая часть писателей при написании своих произведений адресует свои высказывания, как говорится, «своему читателю». В связи с этим данные акты мы назовём коммуникацией (но ещё не назовём общением). И если читатель, прочитав книгу, отреагировал на неё, и его (читателя) реакция дошла до писателя, в этом случае перед нами акты коммуникации-общения (однако такое общение в силу определённых причин в отношении массового читателя происходит весьма редко) [4; 5; 16; 22]. 
Общением, в силу выделенных нами признаков, нельзя назвать акты действий, если реакция читателя произошла (что бывает чаще всего), но по тем или иным причинам не дошла до адресата (писателя). В этом смысле (в смысле общения) адресант-актёр находится в лучшем положении, чем адресант-писатель, ибо адресат первого (зритель) реагирует непосредственно в контактном общении, даже если его реакции - невербальные (жесты, мимика, положение тела, аплодисменты и т.д.).

Если взглянуть на ситуацию с позиции сегодняшнего дня (с его высокоразвитыми технологиями), то обратим внимание на весьма частые «узаконившиеся» акты общения, например, акты общения в чате. Однако общение в чате мы уже отнесём к опосредованному с помощью интернета общению-коммуникации [20; 22]. Так, ещё в XX веке учёные отмечали опосредованное общение как особый вид общения в человеческой деятельности, например, устное общение с помощью телефона [21].

Рассматривая понятия коммуникация/общение, следует обратить внимание также и на бытующий в научной литературе термин косвенная коммуникация. При косвенной коммуникации информационными источниками являются произведения искусства, телевидение, пресса, Интернет и т.д. Анализ данного рода коммуникации приводит нас к мысли, что чтение журналов, книг, просмотр фильмов и рекламы, некоторые формы дистанционного обучения и т.п. также следует рассматривать как косвенные формы коммуникации. Здесь перед нами формы коммуникативного «взаимодействия», когда адресант и адресат включены в коммуникацию не прямо, а косвенно, т.е. посредством авторских произведений. Причём в ситуации, когда лично автор в некотором роде отстранён от процесса коммуникации; адресат же здесь «общается» непосредственно с авторским продуктом (произведением). Такое «общение» мы не можем назвать собственно общением, но коммуникацией назвать можем.

Как отмечалось выше, общение как деятельность осуществляется в различных видах речевой деятельности. То же самое можно сказать и о коммуникации как деятельности. По сути, компонент деятельность здесь выступает как интегративная единица, объединяющая на своей основе, с одной стороны, общение, с другой коммуникацию. И если понятие общение накладывает некоторые ограничения на семантическую структуру, основывающуюся на контактной/дистантной интеракции с учётом устной/письменной форм речевой деятельности, то понятие коммуникация как понятие более широкого содержания таких ограничений не имеет (однако в тех пределах, которые мы определили, собственно, для феномена коммуникации).

Далее, на основе понятий общение/коммуникация, рассмотрим и такое понятие, как межкультурная коммуникация (МК) [19].

Думается, внутренняя форма слова межкультурная указывает на то, что речь идет о коммуникации между представителями разных культур, по крайней мере, двух культур. По старой традиции такая коммуникация, как правило, ранее была дистантной, поэтому носители языка, хорошо чувствующие родное слово, и называли этого рода контакты словом коммуникация.

Поскольку феномен $М К$ (межкультурной коммуникации) определяется через термин коммуникация, надо полагать, что именно этот термин является центральным при рассмотрении процесса взаимодействия участников коммуникации (представителей различных культур). Отсюда на базе коммуникативного взаимодействия/ действия двух и более представителей различных культур и происходит: а) взаимодействие культур; б) обмен культурными ценностями [3].

Подчеркнём, что процесс МК чаще происходит как специфическая форма деятельности (социальной, трудовой, учебной и т.д.), в которую включены, как минимум, две контактирующие культуры/два языка, следовательно, такая коммуникация не ограничивается только знанием ИЯ, но требует знания культуры другого народа, его нравственных норм, ценностных установок и т.д.

В настоящее время, когда расстояния стираются благодаря развитию транспорта, всемирной сети и т.д., в научной литературе мы наблюдаем и такой термин, как межкультурное общение [18]. В целях понимания феномена межкультурное общение, как мы полагаем, необходимо опираться на дифференцированный нами ранее базовый термин общение. И здесь необходимо отметить особую ответственность людей, вступающих в межкультурное общение как деятельность, поскольку сам факт деятельности обязывает осуществлять бесконфликтные контакты, ведущие к решению тех, или иных трудовых/коммуникативных задач.

Всё сказанное относится и к МК/к межкультурному общению при изучении иностранных языков (ИЯ), в том числе и русского языка как иностранного (РКИ) [7]. И тем более это касается учебной МК, обусловленной методологией антропологической лингводидактики (прежде всего её базовым, антропологическим, принципом) [9; 24]. Именно антропологический принцип обязывает вступающих в коммуникацию участников осуществлять корректное взаимодействие, основанное на обмене информацией и социальной перцепции (понимании представителей разных культур друг друга) [3].

Преподаватель, носитель российской культуры и русского языка в заданных условиях, обязан осуществлять, 
как минимум, учебное межкультурное общение на основе знания и понимания национальной культуры своего иностранного учащегося, этнокультуры и языка, формирующих его языковое сознание и механизмы его коммуникативного взаимодействия. С другой стороны, данному преподавателю в учебном общении, в этой самой учебной МК, необходимо эксплицировать важные моменты и российского языкового сознания, организовать работу так, чтобы иностранный учащийся шаг за шагом мог осваивать это новое коммуникативное пространство, связанное с изучаемым для него иностранным языком. И только при такой педагогической стратегии преподавателю удастся подготовить учащегося к успешной реальной МК, к реальному межкультурному общению на РЯ (русском языке) в стране этого языка.

В заключение выделим важнейшие признаки эффективного межкультурного общения/межкультурной коммуникации, обеспечивающие коммуникативное взаимодействие представителей разных этнокультур при решении тех или иных трудовых, политических, коммуникативных задач современной цивилизации:
1. Придание общению/коммуникации статуса деятельности с соответствующей функцией.

2. Формирование умений взаимодействия, обмена информацией и социальной перцепции: а) изучение этнокультур контактирующих народов с формированием качеств толерантности, эмпатии, уважительного и вежливого отношения друг к другу; б) овладение средствами выражения категории вежливости: речевым этикетом и иными средствами культуры общения.

3. Забота о наличии обратной связи, обеспечивающей взаимодействие, обмен информацией, социальную перцепцию.

4. Осуществление коммуникативного взаимодействия как в устном непосредственном общении (назовём его традиционным), так и в письменном при помощи современных технических средств.

5. Включение в общение/в межкультурное общение предметов/компонентов косвенной коммуникации как способа расширения и углубления коммуникативного пространства между коммуникантами, представителями разных этнокультур.

\section{ЛИТЕРАТУРА}

1. Азимов Э.Г., Щукин А.Н. Новый словарь методических терминов и понятий (теория и практика обучения языкам). М.: Издательство ИКАР, 2009. 448 с.

2. Андреева Г.М. Социальная психология. М., 2009. 363 с.

3. Ашчи М., Мухаммад Л.П., Татаринова Н.В. Межкультурная коммуникация как компонент антропологической лингводидактики. Вестник Российского университета дружбы народов. Серия: русский и иностранные языки и методика их преподавания. 2018. Т. 16. № 2. С. 143 - 156.

4. Васюхно Л.П. Чтение как особый вид общения в человеческой деятельности. В книге: Русский язык в общении и образовании. Сборник тезисов, докладов и сообщений международной конференции. 1996. С. 21-21.

5. Волкова С.Н. Прецедентные имена и их роль в художественном тексте. В сборнике: Русский язык в славянской межкультурной коммуникации. Сборник научных трудов по итогам международной научной конференции, посвящённой 75-летию со дня рождения доктора филологических наук, профессора К.А. Войловой. Ответственный редактор 0.В. Шаталова. 2018. С. 62-67.

6. Зимняя И.А. Психология обучения неродному языку (на материале русского языка как иностранного). М., 1989. 220 с.

7. Ипполитова Л.В., Чубарова 0.Э. Подходы к организации обучения русскому языку билингвов в российских вузах. Динамика языковых и культурных процессов в современной России. 2016. № 5. С. 1811- 1816.

8. Китайгородская Г.А. Интенсивное обучение иностранным языкам. Теория и практика. М.: Рус. яз., 1992. - 255 с.

9. Костомаров В.Г., Бурвикова Н.Д. Антропологический принцип как перспектива в развитии лингвострановедения//Русский язык как иностранный: лингвистические проблемы. М., 1997. - С. 8 - 12.

10. Леонтьев А.А. Язык и речевая деятельность в общей и педагогической психологии: Избранные психологические труды. М.: Московский психолого-социальный институт; Воронеж: НПО «МОДЭК», 2001. - 448 с.

11. Мартынова Н.А. Межкультурная коммуникация как особый вид общения. Омский научный вестник. № 2 (54). 2007. С. 148-151.

12. Методика. Заочный курс повышения квалификации филологов-русистов/ Под ред. А.А. Леонтьева. М.: Русский язык, 1988. - 280 с.

13. Митрофанова О.Д., Костомаров В.Г., Вятютнев М.Н., Сосенко Э.Ю., Степанова Е.М. Методика преподавания русского языка как иностранного. М.: Русский язык, 1990. -269 с.

14. Мухаммад Л.П., Мухаммад Х.И.А., Хетагурова Н.Н. К вопросу о методологии современных гуманитарных наук. Вестник МАПРЯЛ. 2006 г. №53. С. 31.

15. Мухаммад Х.И.А. Прагматический компонент «взаимодействие» в аудиторном дискурсе (на материале речи преподавателя). Автореферат диссертации на соискание учёной степени кандидата филологических наук / Государственный институт русского. Москва, 2006.

16. Стародубова 0.Ю. Когнитивные и коммуникативные аспекты культуры речи в медийном дискурсе на фоне прецедентного феномена. В сборнике: Актуальные проблемы культуры речи. сборник научных статей по материалам Всероссийской научно-практической конференции. Отв. Ред. И.С. Папуша. 2019. C. 103- 108.

17. Столетова Е.К. Семантика метаязыковых выражений с лексемой сказать. В сборнике:V Селищевские чтения. международный сборник научных трудов, посвящённый 130-летию со дня рождения Афанасия Матвеевича Селищева. Елец, 2016. С. 237 - 242. 
18. Тарасов Е.Ф. Межкультурное общение - новая онтология анализа языкового сознания// Этнокультурная специфика языкового сознания. М.: Институт языкознания РАН, 1996. С. 7 - 22.

19. Тер-Минасова С.Г. Язык и межкультурная коммуникация. М.: Слово, 2000. Режим доступа: http://www.ffl.msu.ru/research/publications/ter-minasova-langand-icc/ter-minasova-yazik-i-mkk-B00K.pdf

20. Формановская Н.И. Речевое взаимодействие: коммуникация и прагматика. Москва : ИКАР, 2007. 478 с.

21. Формановская Н.И. Русский речевой этикет: нормативный социокультурный контекст. М. : Рус. яз. , 2002. 160 с.

22. Чубарова 0.Э. Имитация общения в блогах при обучении продуктивным видам речевой деятельности. Динамика языковых и культурных процессов в современной России. 2018. № 6. С. 1732- 1736.

23. Щукин А.Н. Методика преподавания русского языка как иностранного: учебное пособие. - М.: ФЛИНТА, 2019. - 508 с.

24. Mukhammad L.P., Tatarinova N.V., Khaleeva 0.N. Modeling a methodology for teaching a foreign language on the principles of anthropological linguodidactics (initial stage of learning). National Academi of Managerial Staff of Culture and Arts Herald. 2019. №1. C. 115 -121.

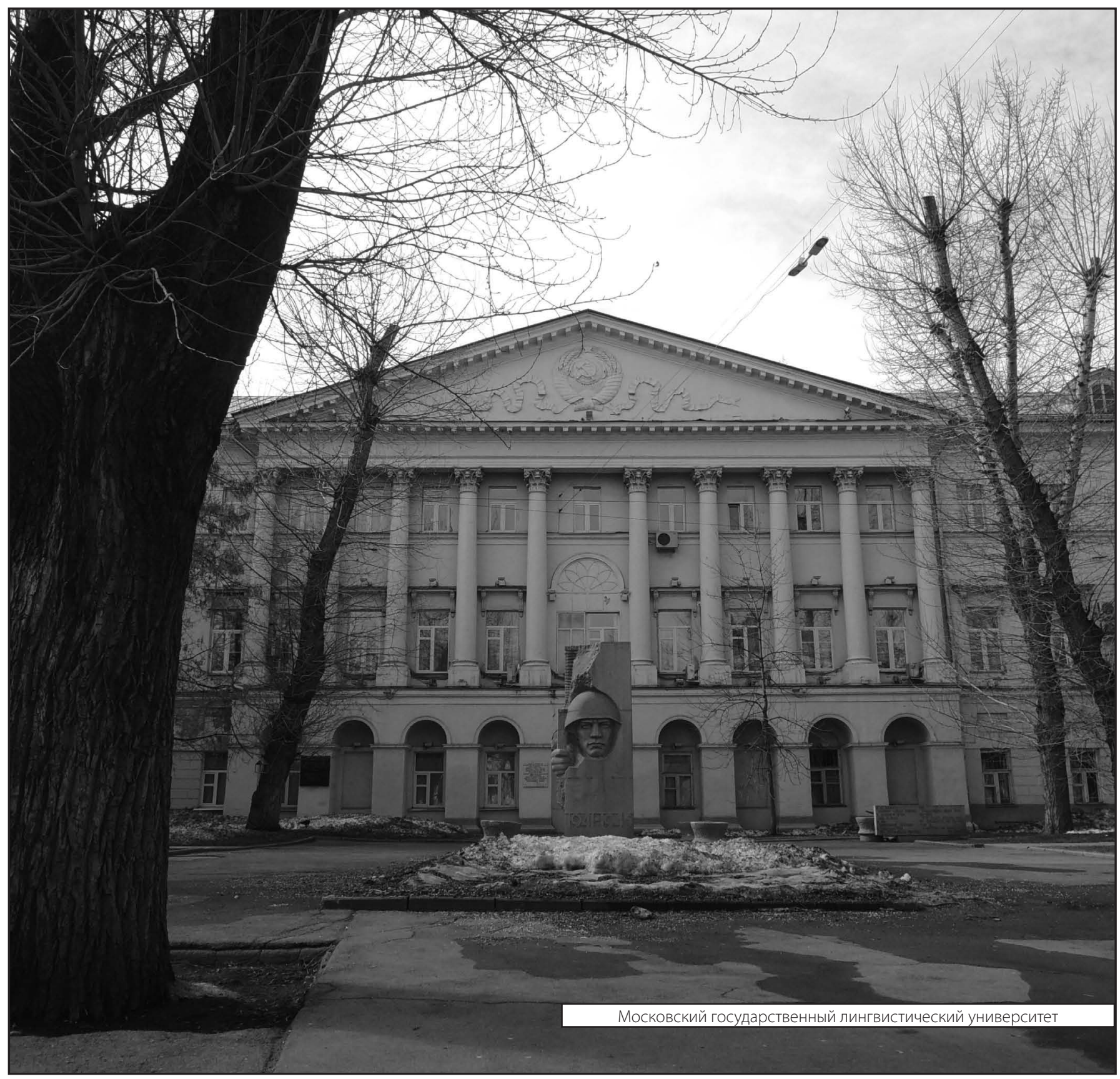

